\title{
Fonološki opis govora grada Gerovo (prema zapisu Božidara Finke) ${ }^{1}$
}

\author{
JANUŠKA GOSTENČNIK \\ Inštitut za slovenski jezik Frana Ramovša ZRC SAZU, Novi trg 4, \\ SI-1000Ljubljana, januska.gostencnik@zrc-sazu.si
}

SCN VI/1 [2013], 38-58

\begin{abstract}
V pričujočem prispevku je prikazan govor kraja Gerovo v Gorskem kotarju v Republiki Hrvaški v obliki fonološkega opisa. Opis sloni na gradivu, ki ga je zbral Božidar Finka leta 1966 za tedanji Srpskohrvatski dijalektološki atlas. Vendar pa v nekaterih primerih ni bilo mogoče $z$ gotovostjo vzpostaviti sistema. Zato je gradivo dopolnjeno $\mathrm{z}$ gradivom, ki je bilo zbrano $\mathrm{z}$ lastnim terenskim delom $\mathrm{v}$ kraju Gerovo. Govor hrvaška dialektologija tradicionalno uvršča med kajkavske govore hrvaškega jezika, vendar pa ta ne izkazuje kajkavskih definicijskih lastnosti, temveč slovenske. Zato se v opisu izhaja iz izhodiščno splošnoslovenskega fonološkega sistema.
\end{abstract}

In this paper the phonology of the dialect of the town of Gerovo in Gorski kotar in Croatia is presented in the form of a phonological description. The description is based on the material collected by Božidar Finka in 1966 for the Serbo-Croatian dialectological atlas. In some cases the system could not be determined, therefore additions were made with the material gathered by the author in the town of Gerovo. Traditionally, Croatian dialectology classifies the speech of Gerovo as a variety of the Kajkavian dialect group, but the Kajkavian determinative characteristics can not be applied to it. However, Slovene characteristics can be. Therefore, in the description of the speech we take the basic Slovene system as a point of departure.

Ključne besede: Gorski kotar, goransko narečje, kajkavsko narečje, fonologija, prozodija

Key words: Gorski kotar, goranski dialect, Kajkavian dialect, phonology, prosody

${ }^{1}$ Opis je govora grada Gerovo nastao prema zapisu dr. Božidara Finke godine 1966. za (tadašnji) Srpskohrvatski dijalektološki atlas. Zapis, napravljen prema Upitniku za Srpskohrvatski dijalektološki atlas, pregledao i pronašao je sve u redu M. Hraste. 


\section{$0 \mathrm{Uvod}^{2}$}

Govor grada Gerovo u Gorskom kotaru u Republici Hrvatskoj hrvatska dijalektologija uvrštava u goranski dijalekt kajkavskog narječja. U fonološkom se opisu proizlazi iz zapisa Božidara Finke. Mjestimice napravljene su dopune građe koje su rezultat vlastitog terenskog istraživanja (ovi su primjeri podcrtani). Naime, građa Božidara Finke ponekad upućuje na to da je govor u postupku gubljenja kvantitativnih opozicija, a i novo prikupljena građa to potvrđuje. Dakle, nova je građa isključivo dopuna staroj (npr. kod jata gdje nema nikakvih nedoumica ${ }^{3}$ nova građa nije napisana jer su refleksi identični onim koje je zapisao Božidar Finka) na mjestima gdje izgleda da refleksi nisu jasni.

$\mathrm{U}$ fonetskoj su transkripciji ovog rada napravljene neke promjene u odnosu na rukopis Božidara Finke, naime:

- grafem $h$ koji označava bezvučni velarni spirant zamijenjen je grafemom $x$,

- grafem $\supset$ zamijenjen je s grafemom $o$ koji je u upotrebi za HJA,

- kad je $u$ dio diftonga (npr. $u o$ ili $u \bar{o}) \mathrm{u}$ ovom je radu uvijek zastupan grafemom $u$,

$-w$ koji označava bilabijalni frikativ zastupan je grafemom $u$.

\section{Prozodija}

\subsection{Inventar}

Fonološki su relevantni samo kvantiteta te mjesto naglaska. Opreka je po kvaliteti ukinuta. Dakle, u inventaru se prozodema pojavljuju samo dva akcenta, dugi i kratki. Nema nenaglašenih dužina. Prema tome, dugi vokali mogući su samo pod akcentom, a kratki mogu biti bilo naglašeni bilo nenaglašeni.

\subsection{Distribucija}

Kratki i dugi naglasak mogu se ostvariti na svakom slogu u riječi osim na otvorenoj ultimi. Nenaglašenih dužina nema.

${ }^{2}$ Tekst je pisan fontom ZRCola koji je na Institutu za slovenski jezik Frana Ramovša ZRC SAZU u Ljubljani razvio Peter Weiss.

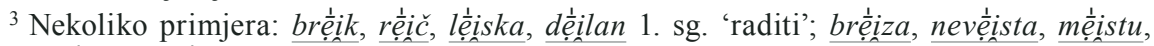
kalệinu, palệinu. 


\subsection{Podrijetlo}

Karakteristična je najprije progresivna metataksa cirkumfleksa. To je tipično slovenski pomak i smatra se prvom izoglosom koja odvaja slovenski jezik od ostaloga južnoslavenskog zapada (Lončarić 1996: 22).

Poslije progresivne metatakse cirkumfleksa idući je akcentski pokret bio povlačenje akcenta sa završnoga otvorenog sloga na prethodeću duljinu (stệina // stệna, zvệizda). Slijedi duženje nekad skraćenog starog akuta izvan ultime

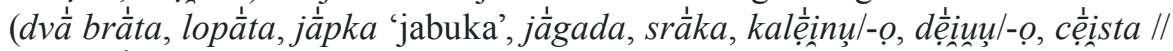
cè̀sta, lệitulu/-o), no, zbog internog razvitka vokala $i$ danas možemo naći na tim slogovima kračinu (kazica 'zdjela, činija', lasica, situ̧).

Došlo je i do drugih akcenatskih pokreta kao što su povlačenje akcenta sa završnoga kratkog otvorenoga sloga na prethodeću kraćinu, dakle na prethodeći $e$ ili $o$ (sln. tzv. »umik na prednaglasno kračino«): ${ }^{4}$ siè stra, žièèna (// žệna), či ểuu/-o (// čệuu) ‘čelo', buōsa (// bộsa) N sg. neodr. f. 'bos'; kronološki kasnije još do povlaćenja akcenta na poluglas u prethodnom slogu (sln. tzv. umik na prednaglasno nadkračino): màgua, mógua 'magla'.

Regresivna metataksa cirkumfleksa daje često, kako bismo i očekivali, kratki slog (sýnu 'sijeno', jimy/-i 'ime', véčir/-yr, vẹčir, dẹvyt, dẹsyt, gásput

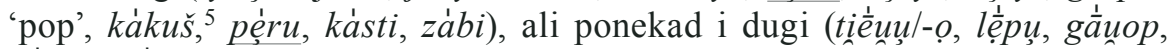
gàuup, kà̄rin) gdje bi mogla dužina biti i posljedica analogije. Ipak, vokalizam pokazuje kako je regresivna metataksa sekundarna što znači da je regresivna metataksa cirkumfleksa relativnokronološki gledajući mlađa od vokalske disimilacije (sýnu) odnosno akanja (gásput, kákuš, káunu), dakle do promjene o $>a$ došlo je prije metatakse.

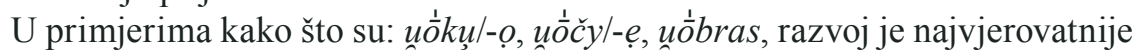
išao ovako: okó > akó > uakồ > uáko > úoko, dakle, možda se radi o pozicijskom razvoju. To nam potvrđuju i primjeri kao što su žấuost 'žalost' in uopàta 'lopata' gdje bi u nenaglašenoj poziciji svakako očekivali vokalsku redukciju (akanje). Teoretički, razvoj bi mogao ići i ovako: okó > uokó > uóko, ali ovim putem ne možemo objasniti primjere kao što je žấuost.

Međutim, vlastita terenska istraživanju pokažu ovakvu sliku: uộku, uóç̌i / uókka, uọ́bras. Dakle, kračinu.

Vjerojatno u isto doba, naime, refleksi su isti, došlo je do povlačenja novog dugog akuta sa završnoga otvorenog ili zatvorenog sloga na pretposljednji $\operatorname{slog}^{7}$ (srámak < psl. *siromáxъ 'siromah', mýxur < psl. *měhúr'b 'mehur').

${ }^{4}$ U ovom ćemo radu upotrebljavati izraz koji je prihvaćen u slovenskoj dijalektološkoj terminologiji, dakle »umično naglašeni $e$ i $o \ll$ (u razdeljku Podrijetlo kraće »um. nagl.«).

${ }^{5}$ Gerovo 2012: kà̄kuš.

${ }^{6}$ Uz dubletu uapàtta.

${ }^{7} \mathrm{Na}$ ovom je mjestu upotrebljen doslovni prijevod izraza kojeg je upotrebio dr. Tine Logar u svojoj raspravi o semiškom govoru u Beloj krajini, dakle umik novega dolgega akuta z zadnjega odprtega in zaprtega zloga na predzadnji zlog (Logar 1996: 206). Naravno, riječ je o govoru u kojem je ukinuta opreka po kvaliteti. Dalje, na istom mjestu, Logar 
Inače, taj je pokret poznat nekim slovenskim dijalektima, naime belokranjskim govorima, kostelskom dijalektu i jednom govoru poljanskog narječja (Javorje nad Poljanami). ${ }^{8}$

Došlo je i do povlačenja kratkog cirkumfleksa (nastalog prema metatoniji iz kratkog akuta porijeklom iz skraćenog starog dugog akuta i novog akuta na kraćini) sa završnoga zatvorenog sloga na pokraćeni pretposljednji slog (buọ̀gat 'bogat' < sln. bogät < psl. *bogätr; výsokl-ak< sln. višök < psl. *vȳsökъ, šýrak $<$ sln. šĭrök < psl. *šìròkъ). ${ }^{9}$

Novi se dugi cirkumfleks odražava kao dužina (mužžñň ak/-ọk 'mali prst',

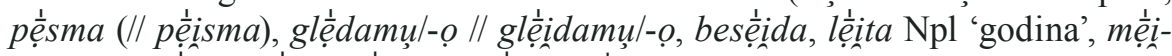

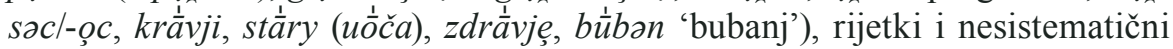
su neki primjeri za kračinu (mlinar 'mlinar').

\section{Vokalizam}

\subsection{Inventar}

Inventar vokala govora grada Gerovo čini po deset jedinica u dugome naglašenome slogu i po deset jedinica u kratkome naglašenome slogu.

\subsubsection{Dugi naglašeni}

$\bar{l}$<smiles>C1=[Ge]C[Ge]1</smiles>

$\bar{u}$

$\bar{o} u$

$\bar{e}$<smiles>[GeH3]</smiles>

kaže »Refleksi novonaglašenih samoglasnikov so isti kot pri umiku dolgega starega cirkumfleksa. To dejstvo dokazuje, da gre v obeh primerih za časovno isti naglasni umik."

${ }^{8} \mathrm{U}$ ovom će se radu u razdeljku Podrijetlo za ovaj pokret upotrebljavati izraz »nakon regresivne (reg.) metatakse dugog akuta«.

${ }^{9} \mathrm{U}$ ovom će se radu u razdeljku Podrijetlo za ovaj pokret upotrebljavati izraz »nakon regresivne metatakse kratkog metatoničnog cirkumfleksa (nakon reg. metatakse met. cirk.)《.

${ }^{10}$ Interpetirati se može i kao ẹ̣ i kao ẹjj. 
2.1.2 Kratki naglašeni

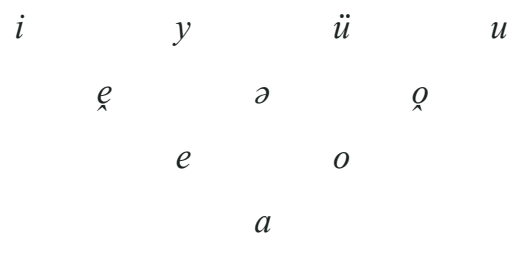

2.1.3 Nenaglašeni

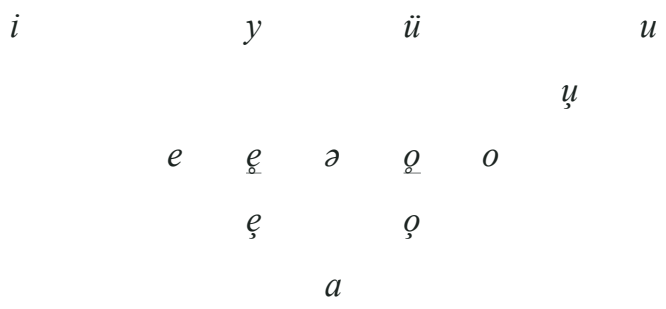

\subsection{Realizacija}

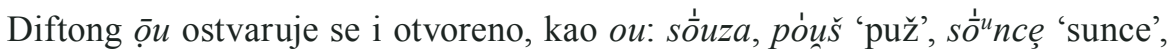
póun 'pun'.

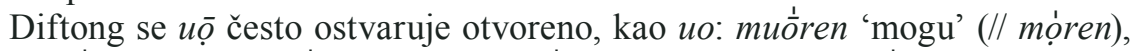

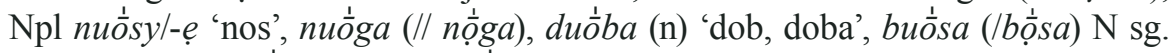
neodr. f. 'bos', puồsư 'posao', puōmmoč 'pomoći', debuōka N sg. neodr. f. 'dubok'.

Diftong $u \bar{o}$ ostvaruje se kao ua u primjeru puà̄por 'papar'.

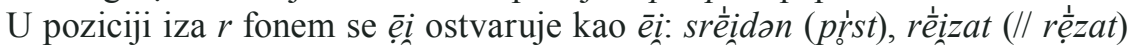
'seći'.

Fonem se $o$ ostvaruje zatvoreno, kao $o$ u primjerima: mọ́ren (// muò̀ren) 1. sg. prez. 'moći', mọgu (// mò̀ugu) 3. sg. pf. m. 'moći', ili kao još zatvorenije $u$

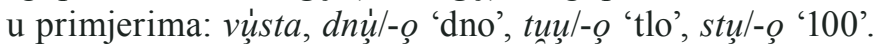

$\mathrm{U}$ poziciji iza $u$ fonem se $a$ u naglašenoj poziciji ponekad ostvaruje kao $a$, dakle kao a pomaknuto nazad prema $o$, u primjerima: unậsy (f.) 'kosa, vlasi' i

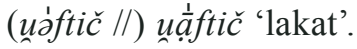

No, vlastit terenski rad pokazuje ponekad labijalizaciju $a$ i u sasvim nevtralnoj poziciji. Ali nigdje labijalizacija nije utoliko uvjerljiva da bismo opravdano mogli ispostaviti a kao poseban fonem. Nekoliko primjera: A pl. za živàali,

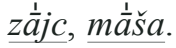




\subsection{Distribucija}

Svi vokali mogu biti naglašeni i nenaglašeni, dok su diftongi uvijek naglašeni i dugi. Nenaglašeni kratki vokali mogu biti i u prednaglasnome i zanaglasnom položaju, dok nenaglašenih dužina nema.

Posljedice su moderne vokalne redukcije:

Vokalska redukcija, tzv. akanje, u primjerima: prednaglasni slog: nasnica, abista 'bubreg', dvarišče 'dvorište', kazica 'zdjela, činija', kašenica, matika 'motika', kabiuna 'kobila', kaščlca 'koštica', pašluat 'slati', dabije, dabiua, paduộjyt, gavarì̄̌ste 'govorite', kalệinul-ọ 'koleno'; zanaglasni slog: jàgada 'jagoda', mrámar ${ }^{11}$ 'rovac'.

\subsection{Podrijet/o ${ }^{12}$}

\subsubsection{Dugi naglašeni}

\begin{tabular}{|c|c|c|}
\hline ger. & izvor & građa \\
\hline \multirow[t]{6}{*}{$\bar{\imath}$} & $<*_{\overline{l_{-}}}$ & 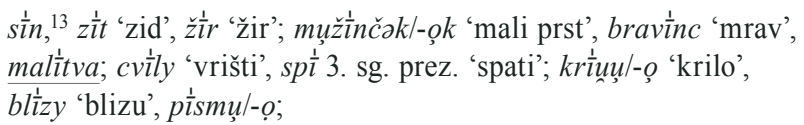 \\
\hline & $<*_{i-}$ & 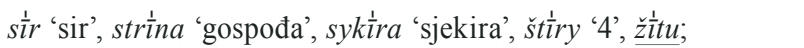 \\
\hline & $<* \bar{e}-$ & 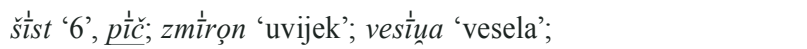 \\
\hline & $<* \grave{e}-$ & 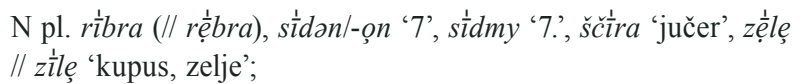 \\
\hline & $<*_{\bar{e}-}$ & 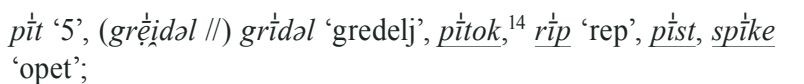 \\
\hline & $<* \grave{-}-$ & dìtęla 'detelina'; 15 \\
\hline
\end{tabular}

${ }^{11}$ Mrámar po disimilaciji iz nar. mramor < psl. *mormorb 'bramor'.

${ }^{12}$ Spojnica na desnoj strani ishodišnog vokal označava da se radi o slogu koji nije ni stražnji ni jednosložan, dakle barem dvosložan. A spojnica na lijevoj strani vokala označava suprotno, to je stražnji slog odnosno jednosložna riječ.

${ }^{13}$ Usp. izvor kratkog i. Vlastito terensko istraživanje dalo je dvojake rezultate, dakle kračinu i dužinu: $\sin i \sin$.

${ }^{14}$ Usp. razvoj ẹi

${ }^{15}$ Usp. izvor $\bar{l}$. 


\begin{tabular}{|c|c|c|}
\hline ger. & izvor & građa \\
\hline \multirow[t]{3}{*}{$\bar{e} \underline{i}$} & $<* \bar{e}-$ & 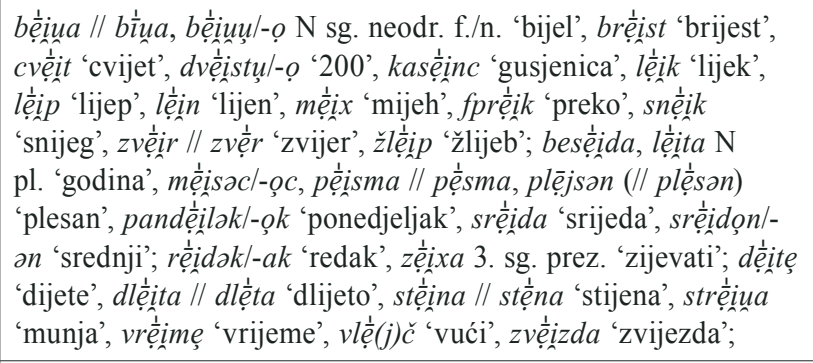 \\
\hline & $<* \grave{e}-$ & 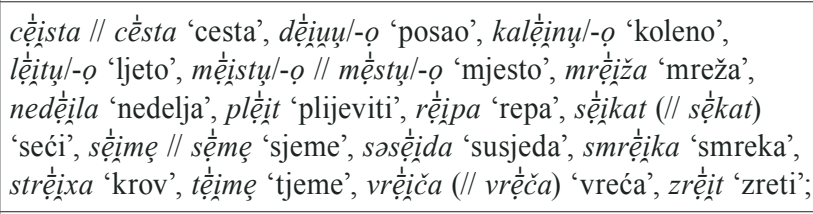 \\
\hline & $<*_{\bar{Q}-}$ & 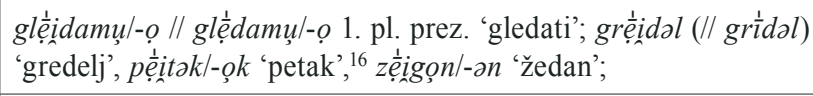 \\
\hline \multirow[t]{4}{*}{$\bar{l}$} & $<*_{\bar{e}-}$ & $\underline{m i} \frac{1}{t}$ 'med'; \\
\hline & $<* \grave{e}-$ & 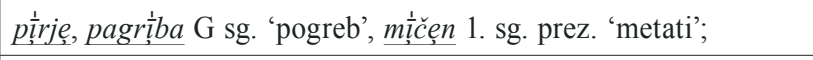 \\
\hline & $<*_{\bar{Q}-}$ & glì dan 1. sg. prez. 'gledati'; \\
\hline & $<* \grave{e}-$ & dịtzlca 'detelina', paklị knit; \\
\hline \multirow[t]{8}{*}{$\bar{e}$} & $<* \bar{e}-$ & 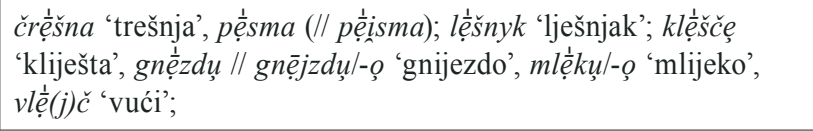 \\
\hline & $<* \grave{e}-$ & $\begin{array}{l}\text { dệt (// dèt) 'deti', nevệsta 'snaha', vệ̀verca, vẹ̣imu 1. pl. prez. } \\
\text { 'znati'; }\end{array}$ \\
\hline & $<*_{\check{e}-}$ & $\begin{array}{l}\text { nakon reg. metatakse cirkumfleksa: dệklẹ 'devojka', lệpus 'adv. } \\
\text { lepo'; }\end{array}$ \\
\hline & $<* \bar{e}-$ & vyčệrja // vyč̀ırija; \\
\hline & $<* \grave{e}-$ & 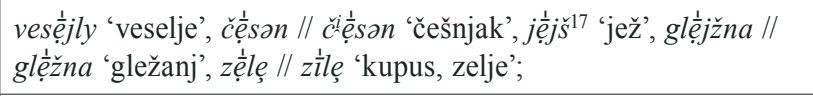 \\
\hline & $<$ um. nagl. $e$ & 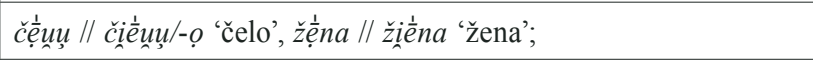 \\
\hline & $<*_{\bar{e}-}$ & 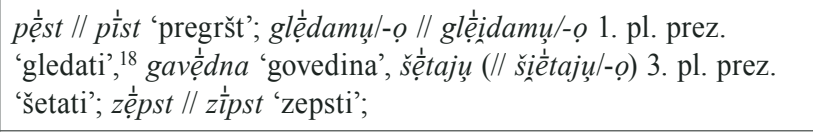 \\
\hline & $<* e_{-}^{-}$ & ardẹ̣ča 'crvena'; \\
\hline
\end{tabular}

${ }^{16}$ Usp. izvor $\bar{\imath}$.

${ }^{17}$ Glas $i$ u ovom i sljedećem primjeru nije sustavni dio diftonga, nego se radi o tzv. prijelaznom $j$. Gledaj razdeljak 3.3 o podrijetlu glasa $j$.

${ }^{18}$ Usp. izvor $\bar{n}$. 


\begin{tabular}{|c|c|c|}
\hline ger. & izvor & građa \\
\hline \multirow[t]{5}{*}{$i \bar{e}$} & $<$ um. nagl. $e$ & 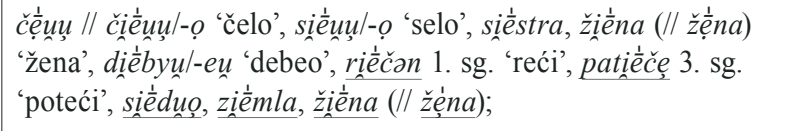 \\
\hline & $\begin{array}{l}<e V^{\prime} \text { ispred } \\
*_{-i}, *_{-} j^{19}\end{array}$ & 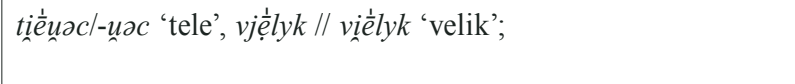 \\
\hline & $<* \check{e}-$ & nakon reg. metatakse cirkumfleksa: tiè êu $u$ /-o 'tijelo'; \\
\hline & $<*_{\bar{e}-}$ & griè da 'greda', nariè dit; \\
\hline & $<* a-$ & u primjeru: diềelẹč 'daleko'; 20 \\
\hline \multirow[t]{7}{*}{$\bar{a}$} & $<* \bar{a}-$ & 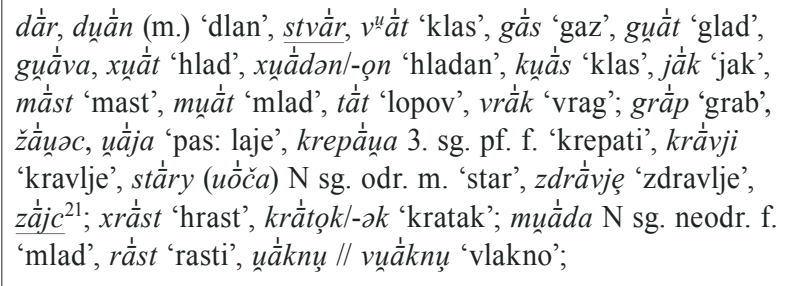 \\
\hline & $<* \grave{a}-$ & 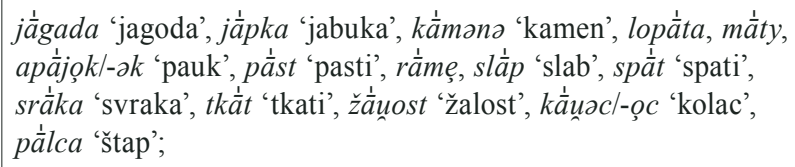 \\
\hline & $<* a-$ & $\begin{array}{l}\text { nakon reg. metatakse cirkumfleksa: blàgo 'stoka, blago', ựăsy } \\
\text { 'kosa, vlasi', zà̄kaj 'zašto'; }\end{array}$ \\
\hline & $<* \bar{\partial}-$ & 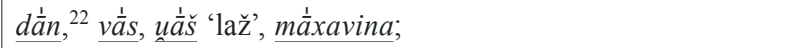 \\
\hline & $<* \dot{j}-$ & mā̄ša 'misa', ${ }^{23}$ pà sjil/-y 'pasji', mà̄lon/-on 'mlin'; \\
\hline & um. nagl. a & stà̀bưul-ọ 'stablo'; \\
\hline & $<*_{O-}$ & $\begin{array}{l}\text { nakon reg. metatakse cirkumfleksa: gà̃uop 'golub', kà̃rin } \\
\text { 'korijen'; }\end{array}$ \\
\hline
\end{tabular}

${ }^{19}$ Regresivna metataksa naglaska iz issln. *-ò kad nije u poziciji ispred sonanta na kraju riječi i iz issln. *-ì kad nije u poziciji iza suglasničkog skupa (ne)sonant + sonant (Šekli 2007: 34).

${ }^{20}$ Razvoj bi prema tome išao ovako: diènlęč $<* *$ dèleč (ponaša se kao tzv. umično nagl. e) $<* *$ delèc $<* *$ dalèc $\leftarrow *$ dalèče) .

${ }^{21}$ Usp. izvor kratkog $a$.

${ }^{22}$ Ibid.

${ }^{23}$ Vlastit terenski rad u ovom leksemu pokazuje a pomaknuto nazad prema o (tzv. labijalizirani $a$ ). 


\begin{tabular}{|c|c|c|}
\hline ger. & izvor & građa \\
\hline \multirow[t]{5}{*}{$u \bar{Q}$} & $<* \bar{Q}-$ & ruộka 'ruka'; \\
\hline & $<* \grave{o}-$ & 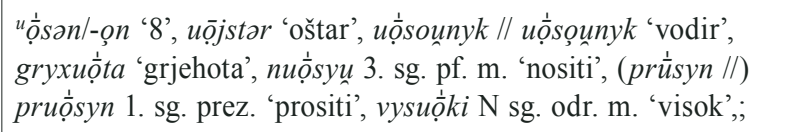 \\
\hline & um. nagl. $o$ & 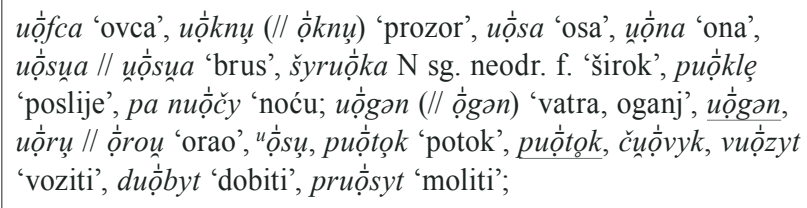 \\
\hline & $\begin{array}{l}<o V \text { ispred } \\
*_{-i} *_{-} \dot{\partial}^{24}\end{array}$ & 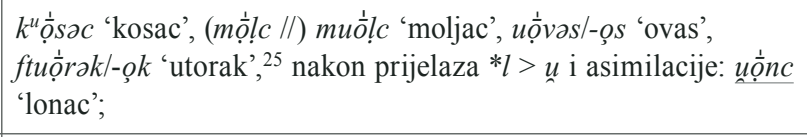 \\
\hline & $<*_{O-}$ & $\begin{array}{l}\text { nakon reg. metatakse dugog akuta: uộfčar 'ovčar'; } \\
\text { nakon reg. metatakse met. cirk.: bu⿳亠丷厂ggat 'bogat', puộtpuat; }\end{array}$ \\
\hline \multirow[t]{4}{*}{$u \bar{o}$} & $<* \grave{o}-$ & (mọren //) muồren 1. sg. prez. 'moći', kuōjn; \\
\hline & um. nagl. $o$ & 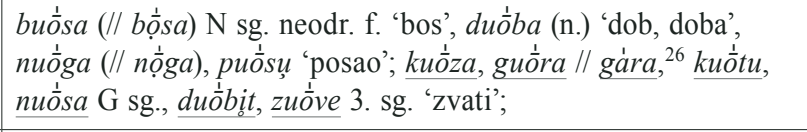 \\
\hline & $\begin{array}{l}<o V \text { ispred } \\
*_{-i} *_{-} \dot{\partial}^{27}\end{array}$ & 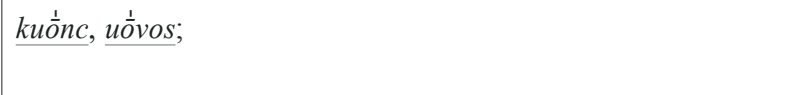 \\
\hline & $<*_{\bar{Q}-}^{-}$ & vuōgu 'ugao';28 \\
\hline \multirow[t]{2}{*}{$\underline{u}$} & $<* \grave{o}-$ & 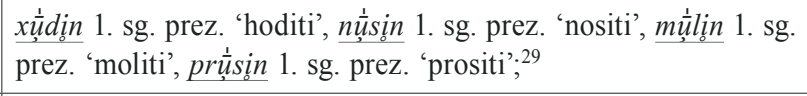 \\
\hline & $<* \grave{Q^{-}}$ & $g \frac{1}{u} b a ;$ \\
\hline \multirow[t]{2}{*}{$\bar{o} u$} & $<* \bar{l}-$ & 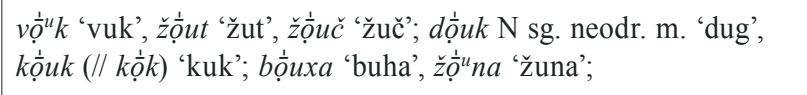 \\
\hline & $<* \grave{l}_{-}$ & vộuna 'pređa'; \\
\hline
\end{tabular}

\footnotetext{
${ }^{24}$ Vidi napomenu 19.

${ }^{25}$ Usporedi Gerovo 2012: tuorok.

${ }^{26}$ Drugi primjer vjerojatno analogija prema kosim padežima (G sg. gári).

${ }^{27}$ Vidi napomenu 19.

${ }^{28}$ Usp. izvor $\bar{o}$.

${ }^{29}$ Usp. izvor dugog $\bar{u}$.
} 


\begin{tabular}{|c|c|c|}
\hline ger. & izvor & građa \\
\hline \multirow[t]{2}{*}{$\bar{o} u$} & $<*{ }_{i}-$ & sṑnce 'sunce'; sồuza 'suza'; \\
\hline & $<* \grave{o}-$ & mò̀ugụ (// mọgự) 3. sg. pf. m. 'moći'; \\
\hline \multirow[t]{4}{*}{$\bar{u}$} & $<* \grave{o}-$ & 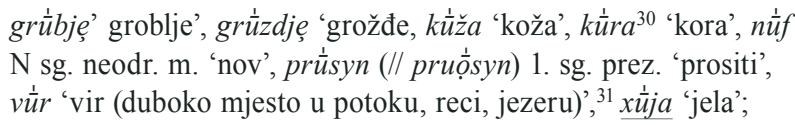 \\
\hline & $<* \bar{o}-$ & 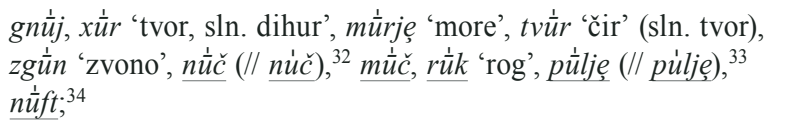 \\
\hline & $<{ }^{*} \bar{Q}-$ & 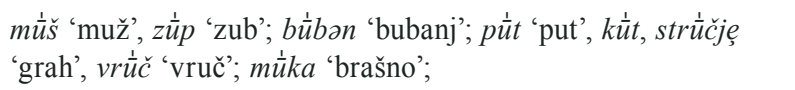 \\
\hline & $<*^{\prime}-$ & 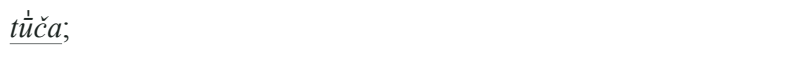 \\
\hline $\bar{o}$ & $<*_{O-}$ & 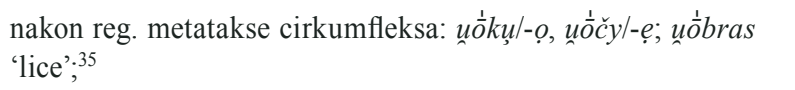 \\
\hline \multirow[t]{3}{*}{$\bar{o}$} & $<* \grave{o}-$ & $\begin{array}{l}\text { pozicijsko nakon asimilacije u primjeru: pauxộzžzn (f paụộžna) } \\
\text { 'ravan' }\end{array}$ \\
\hline & $<{ }^{*} \bar{Q}-$ & 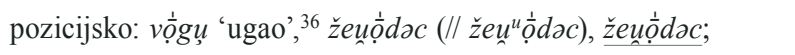 \\
\hline & $<* \bar{\partial}-$ & pozicijsko nakon asimilacije u primjeru: uộ̀vak 'lak'; \\
\hline$(+\bar{r})$ & & G p p⿳亠丷厂⿱⿱亠䒑十纟s $s(/ / p \dot{r} s)$ \\
\hline
\end{tabular}

${ }^{30}$ Vjerojatno vokalizam prikazuje refleks psl. *(s)kòra (glej Be III: 246).

${ }^{31}$ Dugi vokal -u- prikazuje psl. *vorb̀ (b) (usp. sln. vör, vóra 'splav iz debel' u Be IV: 344), iako semantički ne odgovara potpuno.

${ }^{32}$ Usp. izvor kratkog $o$.

${ }^{33}$ Ibid.

${ }^{34}$ Op. cit. 32.

${ }^{35}$ No, vlastita terenska istraživanja ne opravdaju dužine na ovome mjesta, naime rezultat je vlastitog istraživanja kračina u ovim leksemima: uọ ku, uọči/uọ ka, uọbras.

${ }^{36}$ Usp. izvor $u \bar{o}$. 


\subsubsection{Kratki naglašeni}

\begin{tabular}{|c|c|c|}
\hline ger. & izvor & građa \\
\hline \multirow[t]{4}{*}{$i$} & $<*_{i-}$ & 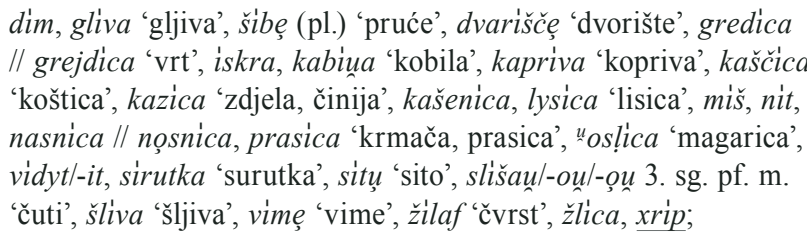 \\
\hline & $<*_{\bar{l}-}$ & $\begin{array}{l}\text { sin; mlinar 'mlinar', matika 'motika', mislin 1. sg. prez. 'vidjeti', } \\
\text { vidyn 1. sg. prez. 'vidjeti', škilyn 1. sg. prez. 'škiljiti', zipka } \\
\text { 'kolijevka'; zima, glista 'glista', grič 'brdo, brijeg', listję 'lišće', } \\
\text { pridən/-ọn 'dobar', nizokk/-ək 'nizak'; puanina 'planina'; }\end{array}$ \\
\hline & $<*_{i-}$ & nakon reg. metatakse cirkumfleksa: jimy/-i 'ime'; \\
\hline & $\leq * \bar{e}-$ & jymina G sg. 'ime'; \\
\hline \multirow[t]{8}{*}{$y$} & $<*_{-} \check{e}$ & býu 'bijel', cýu 'cio', cýn 'jeftin'; \\
\hline & $<* \grave{e}-$ & jyst 'jesti', sýst 'sesti', sýjat 'sejati'; \\
\hline & $<*_{e-}$ & $\begin{array}{l}\text { nakon reg. metatakse cirkumfleksa: sýnu' 'sijeno'; } \\
\text { nakon reg. metatakse dugog akuta: myxur 'mehur'; }\end{array}$ \\
\hline & $<* \hat{e}_{-}$ & srýčzn 'sretan'; \\
\hline & $<*_{i-}$ & $\begin{array}{l}\text { bỳt 'biti', šyt 'šiti', pošỳvat 'podšivati', strýč 'striči', nýč 'ništa', } \\
\text { zdýgnyt 'dignuti'; }\end{array}$ \\
\hline & $<*_{\bar{l}-}$ & týčək (// tičọk) 'ptica'; dývjy 'divlji'; \\
\hline & $<*_{i-}$ & $\begin{array}{l}\text { nakon reg. metatakse met. cirk.: výsọkl-ak // vàsọk 'visok', šýrak } \\
\text { ‘širok’; }\end{array}$ \\
\hline & $<-u$ & ty' 'ovdje'; \\
\hline \multirow[t]{6}{*}{$e$} & $<* e_{-}$ & jètra (// jytra) 'jetra', sprètən/-an 'vješt'; \\
\hline & $<*_{\bar{e}-}$ & raspéluy/-ọ 'križ'; \\
\hline & $<* e^{-}$ & nakon reg. metatakse cirkumfleksa: grènak 'gorak'; \\
\hline & $<*_{e-}$ & $\begin{array}{l}\text { nakon reg. metatakse cirkumfleksa: véčirl-yr 'večer', pérat } \\
\text { 'perad'; }\end{array}$ \\
\hline & $<$ um. nagl. $e$ & médvyt 'medvjed'; \\
\hline & $<*_{\bar{l}-}$ & xrèbac 'brdo, brijeg'; \\
\hline
\end{tabular}




\begin{tabular}{|c|c|c|}
\hline ger. & izvor & građa \\
\hline \multirow[t]{8}{*}{$\underset{s}{e}$} & $<*_{-} \bar{e}$ & zẹt 'uzeti'; \\
\hline & $<*_{-} \dot{e}$ & prẹst 'presti', zèt 'zet'; \\
\hline & $<*_{e}-$ & nakon reg. metatakse cirkumfleksa: mẹvvak/-ək 'mek'; \\
\hline & $<* \grave{e}-$ & brẹja 'breja'; \\
\hline & $<* \check{e}$ & nakon reg. metatakse cirkumfleksa: tẹ́sən/-ọn; \\
\hline & $\begin{array}{l}<* e \\
\text { um. nagl. } e\end{array}$ & pẹcc 'peći', mẹttua 'metla', mẹja 'međa', plẹst 'plesti', jẹelin 'jelen'; \\
\hline & $<* e-$ & $\begin{array}{l}\text { nakon reg. metatakse cirkumfleksa: dẹ̀vyt '9', dẹsyt '10', pẹpyu } \\
\text { 'pepeo', vẹ́syu’veseo', smẹtti 'smeće'; }\end{array}$ \\
\hline & $<* \grave{a}-$ & pozicijsko u primjeru: $z d e ̣ j j$ 'sad(a)'; \\
\hline \multirow[t]{4}{*}{$\partial$} & $<* \dot{\partial}-$ & 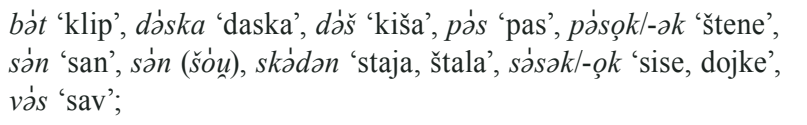 \\
\hline & um. nagl. ə & bàzzk 'bazga', tàma, pàku, màgưa 'magla', ${ }^{37}$ ḋ̀nəs 'danas';38 \\
\hline & $<*_{i-}$ & nakon reg. metatakse met. cirk.: výsọk/-ak // vàsọk 'visok'; \\
\hline & $<* \bar{a}-$ & màjxən 'mali', màstan/-ən, ửftič // uñạfftič 'lakat'; \\
\hline$\partial r$ & $<* \bar{r}-$ & 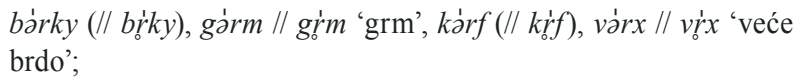 \\
\hline \multirow[t]{6}{*}{$a$} & $<*_{-} \grave{a}$ & $\begin{array}{l}\text { bràt, kràj 'kraj', mràs 'inje', pást 'pasti', pràk 'prag', pràt 'prati', } \\
\text { stàr, stára 'star', tán 'ondje'; }\end{array}$ \\
\hline & $<* \bar{a}-$ & bábjak 'ženskar', zájc 'zec'; \\
\hline & $<* a-$ & $\begin{array}{l}\text { nakon reg. metatakse cirkumfleksa: stvári } \mathrm{G} \mathrm{sg.;} \\
\text { nakon reg. metatakse dugog akuta: pàstyr 'pastir'; }\end{array}$ \\
\hline & $<* \bar{o}-$ & vásək // u’ásọk 'vosak'; \\
\hline & $<*_{-} \grave{o}$ & gràp 'grob', kàjn 'konj', gràst 'grozd', kaš 'koš'; \\
\hline & um. nagl. $o$ & nàva 'nova'; àryx 'orah', pátkuf 'podkev'; \\
\hline
\end{tabular}

${ }^{37}$ Usp. izvor 0 .

${ }^{38}$ Ibid. 


\begin{tabular}{|c|c|c|}
\hline ger. & izvor & građa \\
\hline & $<*_{O-}$ & $\begin{array}{l}\text { nakon reg. metatakse cirkumfleksa: gásput 'pop', kákuš 'kokoš', } \\
\text { kásti; } \\
\text { nakon reg. metatakse dugog akuta: kámarc 'komarac', srámak } \\
\text { 'siromah', gári 3. sg. prez. 'gorjeti'; }\end{array}$ \\
\hline & $<* \bar{\jmath}-$ & dàn 'dan' (pri zvezi dober dan pa dànn), pájn 'košnica'; \\
\hline & $<*_{\partial-}$ & $\begin{array}{l}\text { preuzeto iz hrv. standardnog jezika: táma 'mrak, tama'; } \\
\text { nakon reg. metatakse dugog akuta: mážyn (// mọzžyn) 1. sg. } \\
\text { 'žmuriti'; }\end{array}$ \\
\hline & $<* e-$ & nakon reg. metatakse dugog akuta: ánajst ' 11 '; \\
\hline \multirow[t]{3}{*}{ 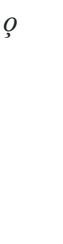 } & $<* \bar{o}-$ & grọ̀m 'grom'; \\
\hline & um. nagl. ə & mógua 'magla', ${ }^{40}$ dónos 'danas'; 41 \\
\hline & $<*_{\partial-}$ & $\begin{array}{l}\text { nakon reg. metatakse dugog akuta: mọžyn (// mážyn) } \\
\text { ‘žmurim'; }\end{array}$ \\
\hline \multirow[t]{4}{*}{$o$} & $<* \grave{o}-$ & vóu 'vol', dóbar (d⿳亠丷ăn) 'dobar'; \\
\hline & $<* \bar{o}-$ & góst 'gost', mózak 'mozak'; \\
\hline & $\leq *_{O}-$ & $\begin{array}{l}\text { nakon reg. metatakse cirkumfleksa: uóku, uóči / uóka, } \\
\text { uọbras; }\end{array}$ \\
\hline & $<* a-$ & $\begin{array}{l}\text { nakon reg. metatakse cirkumfleksa: kòk // kọ̀k 'kako', tòk // tọ̀k } \\
\text { 'tako'; }\end{array}$ \\
\hline$\ddot{u}$ & $<* u-$ & 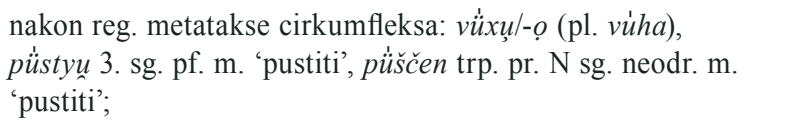 \\
\hline
\end{tabular}

${ }^{39}$ Usp. izvor $\partial$.

${ }^{40}$ Ibid.

${ }^{41}$ Op. cit. 39. 


\begin{tabular}{|c|c|c|}
\hline ger. & izvor & građa \\
\hline \multirow[t]{5}{*}{$u$} & $<* \bar{o}-$ & 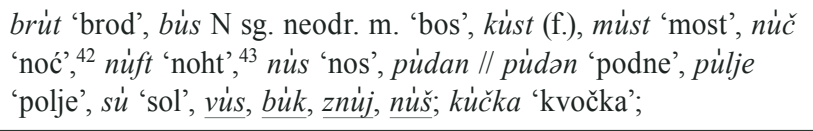 \\
\hline & $<* \grave{o}-$ & kùzji 'kozji', núf $\mathrm{N}$ sg. odr. m. 'nov', nùsi 3. sg. prez. 'nositi'; \\
\hline & $<* \bar{Q}-$ & gúska 'guska', trübəc 'usnja gornja i donja'; \\
\hline & $<* \bar{u}-$ & $\begin{array}{l}\text { sùx ‘suh'; frúška 'kruška', ḷikna 'lokva', jùtry 'sutra'; sùša } \\
\text { 'suša', žùl 'žulj’; }\end{array}$ \\
\hline & $<* \bar{l}-$ & $\begin{array}{l}\text { čùn 'čunak'; } \\
\text { nakon asimilacije i regresivne metatakse cirkumfleksa u } \\
\text { primjeru súdək/- ak 'sladak',44 }\end{array}$ \\
\hline$o$ & $<* \grave{o}-$ & $\begin{array}{l}\text { mọren (// mu⿳亠丷厂ren) 1. sg. prez. 'moći', mọgų (// mồugus) 3. sg. pf. } \\
\text { m. 'moći'; }\end{array}$ \\
\hline \multirow[t]{4}{*}{$u$} & $<* \bar{u}-$ & vưssta; \\
\hline & $<* \grave{o}-$ & u poziciji za $v$ u primjeru: văla; \\
\hline & $<*_{-} \grave{o}$ & 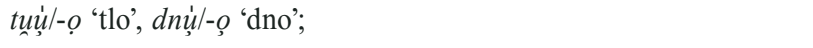 \\
\hline & $<*_{-} \bar{o}$ & stul-o '100', garku/-o, 'toplo'; \\
\hline \multirow[t]{3}{*}{$r$} & $<*_{\bar{r}}$ & 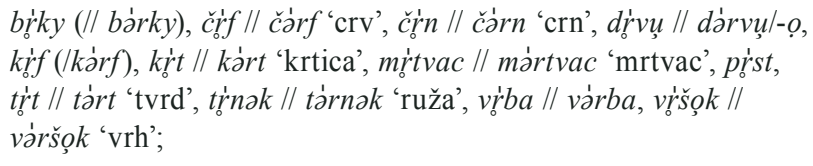 \\
\hline & um. nagl. ə & 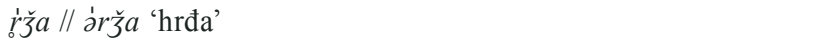 \\
\hline & $<*_{r}-$ & $\begin{array}{l}\text { nakon reg. metatakse cirkumfleksa u primjeru: krivaf // kàrvaf } \\
\text { 'krvav'; }\end{array}$ \\
\hline
\end{tabular}

\subsubsection{Zaključak}

Tzv. stalno dugi i kratko akutirani jat imaju podjednake reflekse i to diftong $(\bar{e} i)$. Iznimka skoro nema. Dakle, došlo je do vrlo ranog duženja kratkoakutiranog jata.

Sekundarno se naglašeni $e$ i $o$ redovito odražaju kao diftongi (i $i \bar{e}$ odnosno uo/uo).

Stalno se dugi $* \bar{e}$ odražava bilo kao dugi vrlo uski $e$, dakle $\bar{l}$, ili već kao dugi $\bar{l}$.

\footnotetext{
${ }^{42}$ Usp. izvor dugog $\bar{o}$.

${ }^{43}$ Ibid.

${ }^{44}$ Razvoj je vjerovatno išao ovako: sủdək/-ak $<*_{\text {sudà } k}<*_{\text {suəda }} \frac{1}{a} k<*_{\text {suada }}$ à $k<*_{\text {sladà }}$ k

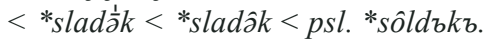


Stalno se dugi $* \bar{o}$ odražava bilo kao dugi $\bar{u}$ bilo kao kratki $u$. Puno ima i

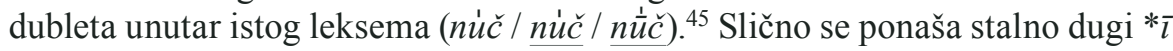
koji reflektira i kao kratki $i$ i kao dugi. Postoje i dublete unutar istog leksema

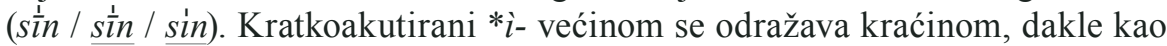
kratki $i$. Prema dvojakim refleksima stalno dugog $*_{o}$ i refleksima stalno dugog *i možemo suponirati da je govor u procesu gubljenja kvantitetnih opozicija.

Stalno se dugi nazal ${ }^{*} \bar{e}$ odražava bilo kao uski dugi $\bar{e}$, dugi $i$ ili kao diftong ẹi. A kratkoakutirani najviše kao dugi vrlo uski $e(\bar{l})$ što možemo zaključiti pomoću novo prikupljene građe.

Stalno se dugi nazal ${ }^{*} \bar{Q}$ odražava kao dugi $\bar{u}$, a kratko se akutirani odražava bilo kao vrlo uski dugi $o$, dakle $\bar{u}$, ili kao dugi $\bar{u}$.

Stalno se dugi $* \bar{a}$ i kratkoakutirani $* \grave{a}$ - odražavaju kao dužina.

Stalno se dugi $* \bar{u}$ i kratkoakutirani $* \grave{u}$ - odražavaju kao kračina.

\subsubsection{Nenaglašeni}

\begin{tabular}{|c|c|c|}
\hline ger. & izvor & građa \\
\hline \multirow[t]{3}{*}{$a$} & $<*_{-} a-$ & $\begin{array}{l}\text { zapùvyt 'zapovijed', küpāvat 'kupovati', sájnan 1. sg. prez. } \\
\text { 'sanjati', rệipa 'repa'; }\end{array}$ \\
\hline & $<* \mathrm{~V}^{\prime}-o-\mathrm{V}^{\prime} 46$ & $\begin{array}{l}\text { gavarì̌ste 2. pl. prez. 'govoriti', kalệinul-o 'koleno', dvarišše } \\
\text { 'dvorište', kabiuna 'kobila'; jàgada 'jagoda', šýrak 'širok'; }\end{array}$ \\
\hline & / & ponekad u preuzetim riječima: blagoslòvyt 'blagosloviti'; \\
\hline \multirow[t]{3}{*}{ u } & $<*_{-O}$ & 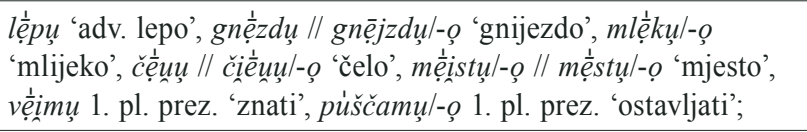 \\
\hline & $<*_{-} Q$ & 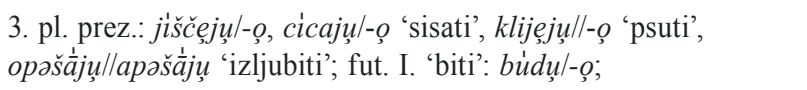 \\
\hline & $<*-a-$ & pozicijski razvoj (asimilacija): unরgà̃ua \\
\hline$\ddot{u}$ & $<* u \mathrm{~V}^{\prime}$ & püstìjưl-o, küpāvat 'kupovati'; \\
\hline \multirow[t]{4}{*}{$u$} & $<* V^{\prime} u$ & mýxur 'mehur'; \\
\hline & $<* o \dot{V}-$ & nakon reg. metatakse cirkumfleksa: gàsput 'pop', kákuš 'kokoš'; \\
\hline & $<*_{-o}$ & vuxu, žżìtu, palệinu; \\
\hline & $<* Q \dot{V}-$ & nakon reg. metatakse cirkumfleksa: ga \\
\hline \multirow[t]{2}{*}{ a } & $<*$ - & 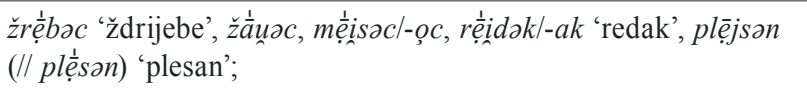 \\
\hline & $<*_{Q-}$ & sasẹ̣ida 'susjeda'; \\
\hline
\end{tabular}

${ }^{45}$ Prvi je primjer od Finke a drugi su ovogodišnji.

${ }^{46}$ Osim u primjerima žă $i$ apăta) a vjerojatno se radi o utjecaju -u- 


\begin{tabular}{|c|c|c|}
\hline ger. & izvor & građa \\
\hline$\underline{o}$ & $<*_{-2}$ & prásoc, puòtok, jầrogk, tuorok, sì \\
\hline \multirow[t]{3}{*}{ o } & $<*_{-\partial}$ & 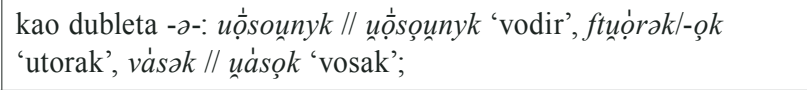 \\
\hline & $<*_{0-}$ & 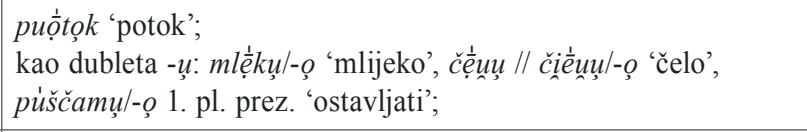 \\
\hline & $<*_{-Q}$ & 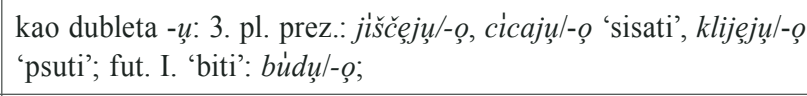 \\
\hline \multirow[t]{2}{*}{$o$} & $<*_{Q-}$ & nakon reg. metatakse cirkumfleksa: gà̄uop 'golub'; \\
\hline & $<* \partial-$ & 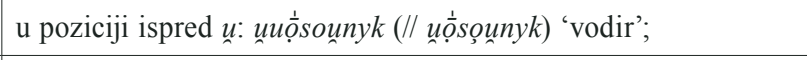 \\
\hline \multirow[t]{4}{*}{$y$} & $<* \check{e}-$ & $\begin{array}{l}\text { sykìra 'sjekira', gryxuộta 'grjehota', jimyt 'imati', médvyt } \\
\text { 'medvjed', àryx 'orah'; }\end{array}$ \\
\hline & $<* e-$ & vyč̣ẹrja // vyčìrja, diè ểbyul-eu 'debeo', jéčmyn/-en; \\
\hline & $<* e-$ & nakon reg. metatakse cirkumfleksa: dẹvvyt '9', dẹsyt '10'; \\
\hline & $<*_{i-}$ & 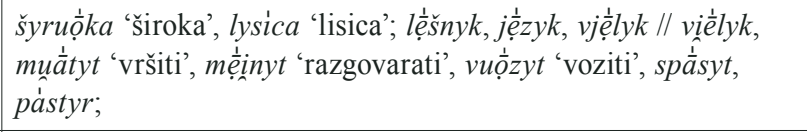 \\
\hline \multirow[t]{2}{*}{$i$} & $<* e-$ & kà̀rin 'korijen', jệlin 'jelen'; \\
\hline & $<*-e$ & u primjeru: zelẹjni 'zelenje'; \\
\hline \multirow[t]{2}{*}{$\underline{i}$} & $<*_{-i}$ & 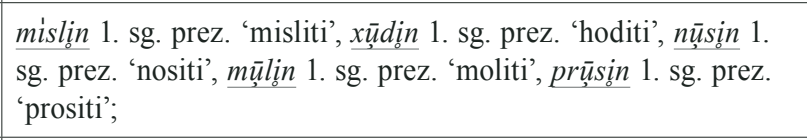 \\
\hline & $<*_{-e}$ & jymmi \\
\hline \multirow[t]{3}{*}{$e$} & $<*_{-e}$ & 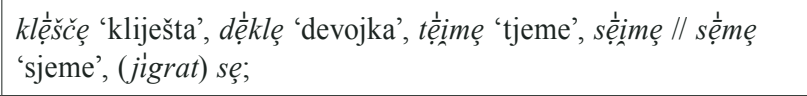 \\
\hline & $<*_{-e}$ & 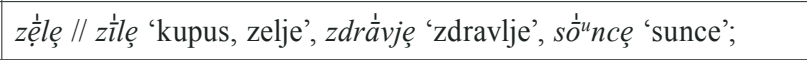 \\
\hline & $<*$ V'e- & dìtę̧la 'detelina', štị̂̀rdessyt '40’; \\
\hline \multirow[t]{2}{*}{$e$} & $<* e \mathrm{~V}-$ & 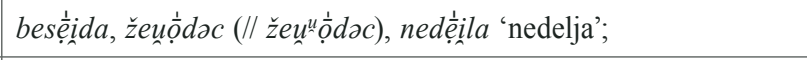 \\
\hline & $<* e e^{\prime}-$ & gredica // grejdica 'vrt'; \\
\hline$\underline{e}$ & $<* \mathrm{~V}-u-\mathrm{V}$ & 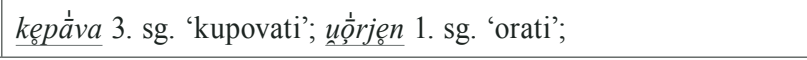 \\
\hline
\end{tabular}

\subsection{Ispad glasova}

\begin{tabular}{|l|l|l|}
\hline$/$ & $<* \mathrm{~V} i$ & xrptệnca 'kičma', pà̀lca ‘štap', gavệ̀dna 'govedina', šišca; \\
\hline & $<* i \mathrm{~V}$ & sràmak; \\
\hline
\end{tabular}




\section{Konzonantizam}

\subsection{Inventar}

\subsubsection{Sonanti}

$\begin{array}{llll}v & & & m \\ & l & r & n \\ j & (l) & & \left(n^{\prime}\right)\end{array}$

\subsubsection{Obstruenti}

$\begin{array}{llll}p & b & f & \\ t & d & & \\ c & & s & z \\ \check{c} & & \check{s} & \check{z} \\ k & g & x & \end{array}$

\subsection{Distribucija}

Zvučni se konsonanti ne mogu naći u finalnome položaju ispred stanke, u tom su se položaju zamijenili bezvučnima (gà̀uop 'golub', muầt). Isto je tako došlo do jednačenja po zvučnosti kad se zvučni konsonant nađe u poziciji ispred bezvučnog (raspélu̧/-o 'križ'). Sonant se $v$ u poziciji ispred konsonanta i u finalnome položaju zamjenio bezvučnim $f$ ( fsému, fprẹ̣ik, žerjā́fka; pátkuf 'podkev', bálaf 'balav, slinav', kŕvaf // kàrvaf).

Rezultati sibilarizacije dokinuti su u deklinaciji (Npl svydáky 'svjedoci',

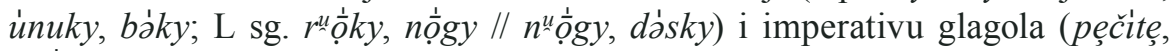
strì žy).

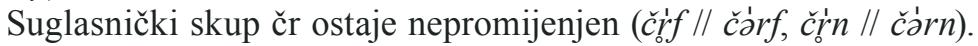

Protetsko $v$ na početku riječi: vǜdrẹ '3. sg. udari', vüxxư/-o 'uho', vúra 'sat'.

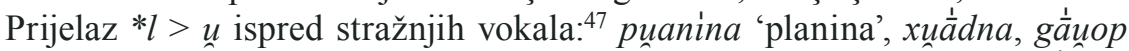

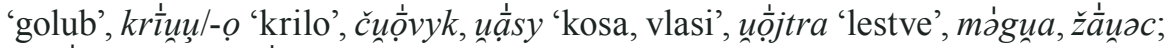
ungà̀ua, adgavarìua. U riječima koje su preuzete iz hrvatskog standardnog jezika do toga prijelaza ne dođe (škuộla). Na početku riječi u prednaglasnom slogu došlo je do asimilacije u primjerima: uṇ̃̂̀vək 'lak', unugà̀ua 'lagala' i užlivoc

${ }^{47} \mathrm{U}$ slovenskoj se terminologiji upotrebljava izraz švapanje. Radi se o prijelazu $* l>u$ ispred stražnjih vokala (tzv. skupina ła), ali ne u poziciji za dentalima. Ovaj je prijelaz karakterističan za slovenski gorenjski dijalekt, koroški dijalekt i govor kraja Babno polje. 
// ǔ̌livac 'lažljivac' (ovaj posljednji primjer mogli bismo objasniti ovim putem: la- > ua- > uo- > uo- > uи - > uи

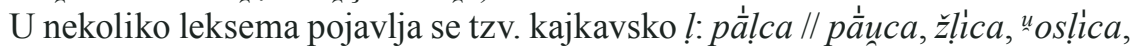
lìkna 'lokva', učitel, mộ̣lc // muò̀lc 'moljac';

Do depalatalizacije je $n j$ došlo u sljedećim primjerima: lùkna 'lokva', ožệnen // ožìñn trp. pr. N sg. m. neodr. 'oženiti'.

\subsection{Podrijetlo}

Konsonanti potječu od odgovarajućih fonema ishodišnog sustava, a osim toga nastali su i sljedećim razvojem:

\begin{tabular}{|c|c|c|}
\hline ger. & izvor & građa \\
\hline$\check{c}$ & $<* t j$ & vrẹ̦iča // vrẹ̣ca \\
\hline$\check{3}$ & $\begin{array}{l}\text { preuzeto iz hrv. } \\
\text { standardnog } \\
\text { jezika }\end{array}$ & ró̧̌ak 'rođak'; \\
\hline \multirow[t]{2}{*}{$f$} & $<* x \mathrm{~K}$ & 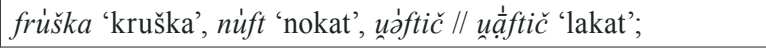 \\
\hline & $<v \mathrm{~K}-,-v$ & 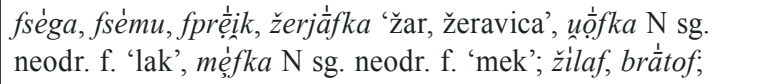 \\
\hline \multirow[t]{3}{*}{$j$} & $<* d j$ & 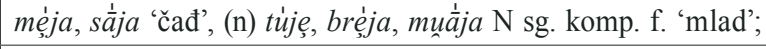 \\
\hline & proteza ispred $i$ - & 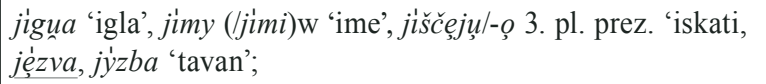 \\
\hline & prijelazni $j^{48}$ & u primjerima ự̣̂jstər, jẹejš ‘jež’, glệjžna // glệžna 'gležanj'; \\
\hline jn & $<* \dot{n}$ & kájn 'konj', pájn 'košnica', sájnan, žàjnemus/-o, zájn; \\
\hline$l$ & $<* i$ & grầble 'grablje', kūplen 1. sg. prez. 'kopati', ka⿳亠丷厂šlat 'kašljati'; \\
\hline$-n$ & $<*-m$ & $\begin{array}{l}\text { sájnan 1. sg. prez. 'sanjati', mážyn (// mọzžyn) 1. sg. prez. } \\
\text { 'žmuriti', zmìrọn 'uvijek'; }\end{array}$ \\
\hline$\dot{n}$ & $<* n$ & u primjerima: zgự àvńik, jáńčkôk/-ək 'jagnje', ńéga G-A 'on'; \\
\hline \multirow[t]{2}{*}{$v$} & $\begin{array}{l}<* \mathrm{~V} x \mathrm{~V} \\
\text { (intervokalno) }\end{array}$ & u primjerima: ự̂̀ vak 'lak', mẹ́vak/-ək 'mek'; \\
\hline & proteza ispred $u$ - & 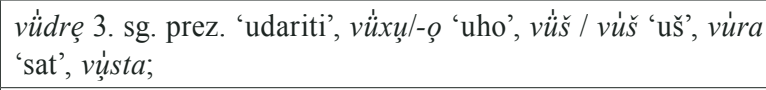 \\
\hline$\underline{u}$ & proteza ispred $o-$ & 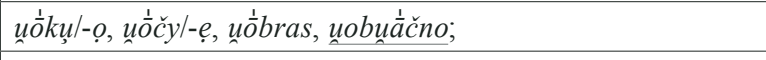 \\
\hline \multirow[t]{2}{*}{$\check{S} \check{S} c$} & $<* s t j$ & pü̈ščen; \\
\hline & $<* s k j$ & jiščesjụ/-o, \\
\hline$\check{z}$ & $<*_{z d j}$ & d’̀šs 'kiša', dəž̃̌lvnyk; \\
\hline
\end{tabular}

${ }^{48}$ Radi se o naknadno umetnutom $j$ koji se najobičnije javlja u naglašenom slogu ispred frikativa ili afrikata. 


\subsection{Ispad glasova}

$p(\check{s})-\rightarrow Q(\check{s})-:$ šenica 'pšenica'

$p(t)-\rightarrow Q(t)-:$ týčak (// tičos) 'ptica'

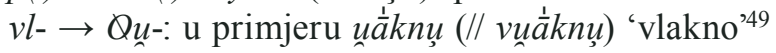

\subsection{Ostale pojave}

\subsubsection{Asimilacija}

\begin{tabular}{|c|c|}
\hline$x \check{c} \rightarrow \check{s} \check{c}$ & nýšče 'nitko', ščl̀r (̌scệêr) 'kći' \\
\hline$x v \rightarrow f$ & fầla 'hvala' \\
\hline$d n \rightarrow g n$ & u primjeru žẹeigna ${ }^{50}$ 'žedna' (po analogiji i m. žẹengonn/-ən) \\
\hline$m r \rightarrow b r$ & u primjeru bravinc 'mrav' \\
\hline$t i \rightarrow k$ & u primjeru kệidon/-an 'tjedan's1 \\
\hline$\hat{x}-\check{s} \rightarrow \check{s}-\check{s}$ & u primjeru $\check{s i s ̌ s} a$ 'kuća'52 \\
\hline$s-\check{S} \rightarrow \check{S}-\check{S}$ & u primjeru pašì \\
\hline$S-\check{c} \rightarrow \check{S}-\check{c}$ & u primjeru nùušeča 'trudna' \\
\hline$z-\check{c} \rightarrow \check{z}-\check{c}$ & u primjeru mưž̀̀nčak/-ọk 'mali prst' \\
\hline
\end{tabular}

\subsubsection{Disimilacija}

$-t l-\rightarrow-k l-$ u primjeru puộklẹ 'poslije'

\section{LITERATURA}

Vida BARAC-GRUM, 1993: Čakavsko-kajkavski govorni kontakt u Gorskom kotaru. Rijeka.

France BEZLAJ, 1977-2007: Etimološki slovar slovenskega jezika I-V. Ljubljana: Mladinska knjiga.

Vladimir DYBO, 1982: O nekotoryh akcentologičeskih izoglassah slovensko-kajkavskoj jazykovoj oblasti. Hrvatski dijalektološki zbornik 6. Zagreb: JAZU Razred za filološke znanosti. 101-134.

${ }^{49}$ Razvoj je najvjerojatnije išao prijeko prijelaza $* l>u$ i asimilacije što je rezultiralo $u$

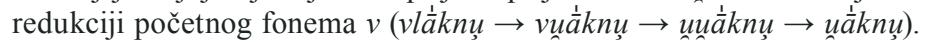

${ }^{50}$ in $>d n>g n$

${ }^{51} \mathrm{U}$ primjeru se spýk (spì̀ke) 'opet' vjerovatno radi o prijelazu $t \rightarrow k$. O tome piše Ramovš (Ramovš 1924: 227), ali govori samo o prijelazu $t \rightarrow k$ ispred $i$ (npr. proti $>$ proki).

${ }^{52} \mathrm{U}$ slovenskoj je terminologiji to tzv. narečna palatalizacija, dakle promjena velara $k, g$, $h>\check{c}, j, \check{s}$ ispred prednjih vokala. 
Anita CELINIČ, Ankica ČILAŠ ŠIMPRAGA, 2008. Govor Jurkova Sela u Žumberku. Rasprave Instituta za hrvatski jezik i jezikoslovlje 34/1. Zagreb: Institut za hrvatski jezik i jezikoslovlje. 63-93.

Božidar FINKA, 1974: Gorskokotarska kajkavština u našem dijalekatskom mozaiku. Kajkavski zbornik. Zlatar. 29-43.

Božidar FINKA, Vida BARAC-GRUM, 1984-1991: Rječnik hrvatskoga kajkavskoga književnog jezika. Zagreb.

Pavle IVIČ, 1961: Prilozi poznavanju dijalektske slike zapadne Hrvatske. Godišnjak Filozofskog fakulteta u Novom Sadu. Knjiga VI. Novi Sad: Filozofski fakultet. 191-212.

Josip LISAC, 2006: Tragom zavičaja: delnički govor i govor Gornjih Turni u svjetlosti goranskih kajkavskih govora. Split.

Josip LISAC, 1989. Prozodija goranskih kajkavaca. Radovi akademije nauka i umjetnosti Bosne i Hercegovine 84. Sarajevo: Akademija nauka i umjetnosti Bosne i Hercegovine. 241-249.

Mijo LONČARIĆ 1996: Kajkavsko narječje. Zagreb: Školska knjiga.

Tine LOGAR, 1996: Dialektološke in jezikovnozgodovinske razprave. Ljubljana: ZRC SAZU.

Marija MALNAR, 2010: Dijalekti u Gorskom kotaru. Rasprave Instituta za hrvatski jezik i jezikoslovlje 36/1. Zagreb: Institut za hrvatski jezik i jezikoslovlje. 47-69.

Tijmen PRONK, 2010: Rani razvoj goranskih govora. Rasprave Instituta za hrvatski jezik i jezikoslovlje 36/1. Zagreb: Institut za hrvatski jezik i jezikoslovlje. 97-133.

Fran RAMOVŠ, 1936: Kratka zgodovina slovenskega jezika. Ljubljana.

Fran RAMOVŠ, 1924: Historična gramatika slovenskega jezika 2. Konzonantizem. Ljubljana: Učiteljska tiskarna.

Fran RAMOVŠ, 1920: Historična gramatika slovenskega jezika. Ljubljana: Društvo slušateljev filozofske fakultete.

Petar SKOK, 1988: Etimologijski rječnik hrvatskoga ili srpskoga jezika. Zagreb: JAZU: Globus.

Marko SNOJ, 2009: Slovenski etimološki slovar. Ljubljana: Modrijan: Založba ZRC.

Christian STANG, 1957: Slavonic accentuation. Oslo.

Matej ŠEKLI, 2013: Zemljepisnojezikovna členitev kajkavščine. Slovenski jezik Slovene linguistic studies 9 . V tisku.

Matej ŠEKLI, 2007: Naglasni sestav govora vasi Jevšček pri Livku nadiškega narečja slovenščine v luči relativne kronologije. Škrabčeva misel VI: zbornik s simpozija. 19-36.

Matej ŠEKLI, 2005/2006: 1. Zgodovinska doba Rekonstrukcija praslovanskega naglasnega sestava (delovna različica za interno uporabo) Vaje iz predmeta Primerjalna slovnica slovanskih jezikov III: Slovansko naglasoslovje. Univerza v Ljubljani: Filozofska fakulteta, Oddelek za slavistiko. 


\section{FONOLOŠKI OPIS GOVORA KRAJA GEROVO}

Prikazan je govor kraja Gerovo v Gorskem kotarju v Republiki Hrvaški v obliki fonološkega opisa. Opis sloni na gradivu, ki ga je zbral Božidar Finka leta 1966 za tedanji Srpskohrvatski dijalektološki atlas, in na gradivu, zbranim z lastnim terenskim delom. Tradicionalno gledano govor Gerova hrvaška dialektologija uvršča v zahodno goransko podnarečje goranskega narečja kajkavske narečne skupine hrvaškega jezika (t. i. zapadnogoranski poddijalekt goranskog dijalekta kajkavskog narječja), vendar pa govor ne izkazuje niti ene od osnovnih kajkavskih definicijskih lastnosti (t. i. »osnovna kajkavska akcentuacija oz. OKA, sovpad odrazov za psl. *ě in *ə, sovpad odrazov psl. *o in *l). To se v hrvaški dialektologiji opravičuje s slovenskimi vplivi na ta govor (bodisi naj bi šlo za »pokajkavljene« oz. "poslovenjene« begunce pred Turki, ki so se zatekli v Slovenijo, nato pa so se njihovi potomci vrnili nazaj v Gorski kotar, bodisi naj bi šlo za slovenske delavce, ki so bili pripeljani iz Slovenije za časa Petra Zrinskega). Na osnovi genetskih meril, tj. starejših slovenskih jezikovnih sprememb, oz. na podlagi definicijskih lastnosti slovenščine (kot so splošnoslovenski pomik cirkumfleksa oz. splošnoslovenska progresivna metataksa cirkumfleksa, splošnoslovenski umik naglasa s končnega zloga na prednaglasno dolžino, paralelna diftongizacija issln. ${ }^{*} \bar{o}$ in issln. $* \bar{e}$, daljšanje issln. kratkih akutiranih zložnikov v nezadnjem besednem zlogu v zahodnih in južnih slovenskih narečjih) pa lahko sklepamo, da gre za slovenski govor. 